Research Article

\title{
Particle Flow Analysis of the Influences of Joints on Rock Mechanical Properties
}

\author{
W. R. Liu ${ }^{1,2}$, H. F. Ma ${ }^{1,2, *}$, C. M. Li ${ }^{1,2}$, J. Z. Li ${ }^{1,2}$, Z. Q. Yin ${ }^{1,2}$, Y. Li ${ }^{4}$ and C. Wang ${ }^{3}$ \\ ${ }^{I}$ Key Laboratory of Safety and High-efficiency Coal Mining, Ministry of Education, Anhui University of Science and Technology, \\ Huainan, 232001, China \\ ${ }^{2}$ Anhui Province Key Laboratory of Mining Response And Disaster Prevention And Control In Deep Coal Mine, Anhui University of \\ Science and Technology, Huainan Anhui 232001, China \\ ${ }^{3}$ Graduate School of Engineering, Nagasaki University, Nagasaki, 852-8521, Japan \\ ${ }^{4}$ School of Resource and Safety Engineering, China University of Mining and Technology, Beijing, 100083, China
}

Received 8 June 2016; Accepted 1 November 2016

\begin{abstract}
The failure of natural rock mainly forms along the joint planes; therefore, the existence of joints heavily affects the rock strength. The influences of joints with a different dip angle and cross double joints on rock mass strength were analyzed using theoretical calculation and particle flow PFC2D software to explore the mechanical properties of joints on rock failure. Results show that the strength of a jointed rock has obvious angle-range effects in the uniaxial compression text, and the peak strength of rock specimens is typical of the " $U$ " type with the increase of the joint dip angle. For the rock mass of cross double joints, the rock mass strength is determined by the strength of joints when the joint dip angle of either joint is between $45^{\circ}$ and $75^{\circ}$. The rock mass strength is determined by the superposition of the effects of these two joints when the joint dip angles of the two joints are both between $45^{\circ}$ and $75^{\circ}$; the influences of joints on the rock mass strength are not obvious when neither of the joint dip angles of the two joints is between $45^{\circ}$ and $75^{\circ}$. The conclusions obtained in the study have significant implications for understanding the laws of joint rock strength.
\end{abstract}

Keywords: Jointed rock mass, PFC2D, Compression test, Joint dip angle, Cross double joints

\section{Introduction}

With the rapid development of geotechnical engineering at home and abroad, the rock regions are chosen to build an increasing number of priority projects. Therefore, the study of rock mass has become a focus for study and development worldwide. Rock mass, a complex geological body, is generated after a long geological history. During the entire historical process of rock mass formation, under the effects of the geological tectonic stress field, natural rock masses usually contain several joints and cracks on a discontinuous structural surface, which results in high complexity, heterogeneity, discontinuity, and anisotropy of these materials. Rock mass is well-known as being composed of complete rock mass and discontinuous structural planes. The mechanical properties of the rock mass and the engineering stability are greatly influenced by the discontinuous structural planes. The joint is a common structural plane. The instability failure of rock and soil engineering and the coal mine roof fall are not controlled by the strength of the intact rock masses but by the degree of the development of the joints and fissures in the rock masses. Studying the strength and failure characteristics of jointed rocks is significant. The joints and weakness planes notably influence the rock mass strength. Additionally, the structural surface of the rock mass often results in great differences in the physical and mechanical properties. Therefore, studying the influences of joints on rock mechanical properties has

*E-mail address: 970357296@qq.om

ISSN: $1791-2377 @ 2016$ Eastern Macedonia and Thrace Institute of Technology. All rights reserved. practical significance in engineering practice.

\section{State of the art}

The mechanical properties of jointed rock mass are complex. The strength and deformability of the rock mass are heavily influenced by the distribution of joints; the failure modes also significantly vary with the variation of joint orientation, angle, and number. Many scholars have performed numerous extensive studies on the jointed rock mass. Using the artificial jointed rock specimens, Wong [1] and Yang [2] performed the uniaxial compression test on the discontinuous jointed rock mass and determined the failure mechanism. However, the specimen preparation process is strict, guaranteeing the original mechanical properties of the joint; moreover, the test time periods are long, the operation is complicated, and the fracture mechanism cannot be revealed from a microperspective. In recent years, with the rapid development of computer technology, the numerical calculation method has been widely used in geotechnical mechanics. Discrete element method (DEM) was first proposed by Cundall [3]. The particle flow code in two dimensions (PFC2D) is a powerful tool for simulating solid mechanics, large deformations, and particle flow problems, as well as the microscopic failure mechanism, which compensates for the disadvantages of laboratory tests. The method of PFC2D has achieved substantial progress in rock mechanics research. Many scholars studied the mechanical behavior of sandy soil and obtained the effects of sandy microscopic parameters on macromechanical behavior [4], [5], [6]. Eberhardt[7] and Wang [8] established a discrete 
element numerical analysis model of a rock slope with regular joints and a soil-similar slope with weak intercalated layers and analyzed the influences of a joint connectivity rate and a weak surface structure on the slope failure mode. Prudencio [9], Vergara [10], and Ghazvinian [11] achieved some interesting results by analyzing the effects of the rock bridge length and joint length on the fracture form and mechanical properties of a discontinuous jointed rock. $\mathrm{Wu}[12]$ built an equivalent rock model that reflects the distributive characteristics of joints to study the mechanical properties of rock mass strength, by means of the particle flow software. Based on the PFC2D software, Park [13] and Bahaaddini [14] conducted the direct shear test experimental study for the rock mass that contains natural rough joints, obtained the shear strength of the coupling joints, and revealed the failure process from the microscopic view.

An analysis of the above references focused on the discontinuous joints and the mechanical parameters of the joint plane itself, whereas there was little previous literature about the influences of different joint dip angles and cross double joints on the mechanical properties of the rock mass. Therefore, in this present study, the effects of the joint with different dip angles on the rock mass strength were analyzed by theoretical calculation, and the uniaxial compression model of the rock mass was established by the microparticle flow PFC2D software to thoroughly analyze the effects of the joint with different dip angles and the cross double joints on the mechanical properties of the rock mass.

The remainder of this paper is organized as follows. Section 3 establishes the mechanical models of the single joint with different dip angles based on a theoretical analysis and deduces the effects of the joints with different dip angles on rock strength. This section also establishes the uniaxial compression numerical models of the single joint with different dip angles and cross double joints by the numerical simulation method. Section 4 analyzes the effects of joints with different dip angles and cross double joints on rock mass strength and failure characteristics. Section 5 summarizes the conclusions.

\section{Methodology}

\subsection{Theoretical analysis of joint plane on mechanical} properties of rock mass

When the rock mass only has a single joint and is affected by an external force, normal stress $\sigma$ and shear stress $\tau$ appeared on the joint plane, as shown in Fig. 1(a); the values of $\sigma$ and $\tau$ differ with the different principal stress and the angle $\beta$ between the maximum principal plane and the joint plane. Fig. 1(b) is the Mohr's stress circle under the action of the single joint. When the rock mass is subject to the normal stress $\sigma_{1}$ and $\sigma_{3}$, the coordinates of point $\mathrm{B}$ on the stress circle can be expressed as follows [15]:

$$
\left\{\begin{array}{l}
\sigma=\frac{1}{2}\left(\sigma_{1}+\sigma_{3}\right)+\frac{1}{2}\left(\sigma_{1}-\sigma_{3}\right) \cos (2 \beta) \\
\tau=\frac{1}{2}\left(\sigma_{1}-\sigma_{3}\right) \sin (2 \beta)
\end{array}\right.
$$

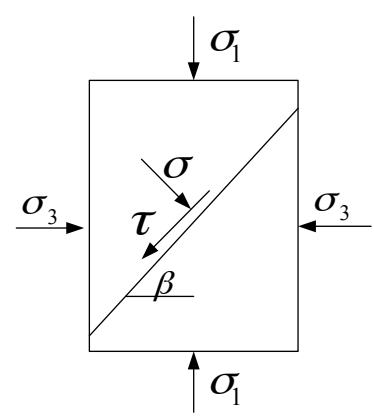

(a)

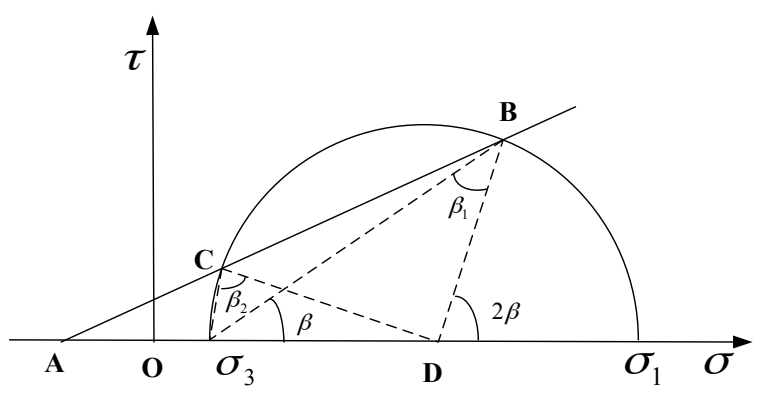

(b)

Fig. 1. (a) Compression failure model of single jointed rock mass (b) Mohr's stress circle

Based on the Coulomb criterion, if the $\mathrm{ABC}$ curve is the strength curve as shown in Fig. 1(b), the formula of the strength of the joint plane can be expressed as:

$$
\tau_{i}=\sigma \tan \varphi_{i}+C_{i}
$$

where $\mathrm{C}_{i}$ is the cohesion of the joint plane, and $\varphi_{i}$ is the internal friction angle of the joint plane.

From Fig. 1(b), the point B on the stress circle lies right on the strength curve, and the joint plane is in the condition of the limit stress equilibrium. Under such circumstances, the shear slip failure is formed along the joint plane. When the value of $\beta$ is between $\beta_{1}$ and $\beta_{2}$ and point $\mathrm{B}$ is above the ABC curve, the shear stress $\tau$ appearing on the joint plane is larger than the shear strength of the joint plane. Thus, the rock mass will be a failure along the joint plane by slipping. When $\beta$ is greater than $\beta_{1}$ or less than $\beta_{2}$, point $\mathrm{B}$ is below the ABC curve, and the shear stress $\tau$ appearing on the joint plane is less than the shear strength of the joint plane. Resultantly, the rock mass will not form a slip failure along the joint plane.

Based on the Coulomb criterion of the strength of the joint plane and the Mohr stress circle theory, the condition of the forming slip failure along the joint plane $\mathrm{AB}$ is as follows:

$$
\sigma_{1}=\sigma_{3}+\frac{2\left(\mathrm{C}_{\mathrm{i}}+\sigma_{3} \tan \varphi_{i}\right)}{\left(1-\tan \varphi_{i} \cos \beta\right) \sin (2 \beta)}
$$

The value of $\beta$ can be solved by Formula (3). According to Formula (3), the derivative of $\beta$ is taken, and the derivative that is equal to zero is set. Then, the angle corresponding to the minimum strength of the jointed rock is:

$\beta_{0}=45^{\circ}+\frac{\varphi_{\mathrm{i}}}{2}$ 
W. R. Liu, H. F. Ma, C. M. Li, J. Z. Li, Z. Q. Yin, Y. Li and C. Wang/

Journal of Engineering Science and Technology Review 9 (5) (2016) 164-170

Theoretical analysis shows that the rock mass of the single joint has angle-range effects. The rock mass forms a moving shear failure along the joint plane only when the value of $\beta$ is between $\beta_{1}$ and $\beta_{2}$. If $\beta$ is greater than $\beta_{1}$ or less than $\beta_{2}$, the failure of the rock mass most likely will not form along the joint plane but along the other section which is intersected with the joint plane; the influences of the joint on the failure are little. In addition, the angle corresponding to the minimum strength of the jointed rock is $\beta_{0}$. Thus, the numerical results coincide well with the theoretical calculation results.

\subsection{Numerical analysis of the joint plane on the} mechanical properties of rock mass

The effects of the different joint angles and double cross joints on the rock mass strength are investigated using the particle flow theory and numerical model parameter calibration; the uniaxial compression numerical model of the jointed rock mass is based on the particle flow theory.

\subsubsection{Particle flow profile}

The PFC2D model is an aggregation of discrete rounded particles [4]. Based on the DEM, the calculations performed in the DEM alternate between the application of Newton's second law to the particles and a force displacement law at the contacts [3]. The particle flow code (PFC) presents three contact constitutive models, which are the slip, contact stiffness, and bonding models. There are two bonding models, namely, contact bonding and parallel bonding models, to simulate the damage of the particle bonding [6]. Contact bonding refers to the bonding between the particle points; the force can only be generated when the particle demonstrates relative displacement. Contact bonding can only transmit forces acting at the contact point. Parallel bonding can transmit both forces and moments between particles. Thus, parallel bonding may contribute to the resultant force and the moment acting on the two bonded particles and can be applied to compact materials, such as rocks. If the maximum tensile stress exceeds the normal strength or the maximum shear stress exceeds the shear strength, the parallel bonding breaks. The progressive destruction of bonding is the process of macrofailure.

\subsubsection{Macroscopic and microscopic mechanical parameters of rock}

Particle flow theory represents the macroscopic physicomechanical properties of rocks as their microscopic physicomechanical properties. However, the microscopic parameters of rocks do not directly correspond to their macroscopic parameters. The microscopic parameters were checked and corrected prior the numerical simulation of the uniaxial compression model. During this process, the uniaxial compression test was first performed, and then the stress-strain curves of the rock samples were obtained. Next, the microscopic parameters of the numerical simulation model were repeatedly adjusted to make the numerical simulation curves close to the laboratory test curves. When both curves were close to coinciding, the microscopic parameters can accurately reflect the macroscopic mechanical parameters as illustrated.

In this study, the siltstone in the Huainan coal mine area was tested; the test equipment and the loading process are shown in Fig. 2. The rock stress-strain curves and mechanical parameters were obtained by a laboratory test. Based on the numeral simulation software, the siltstone microscopic parameters (Table 1), repeatedly adjusted via trial and error, were obtained. The final failure model (Fig. 3) and the stress-strain curves (Fig. 4) were also obtained.

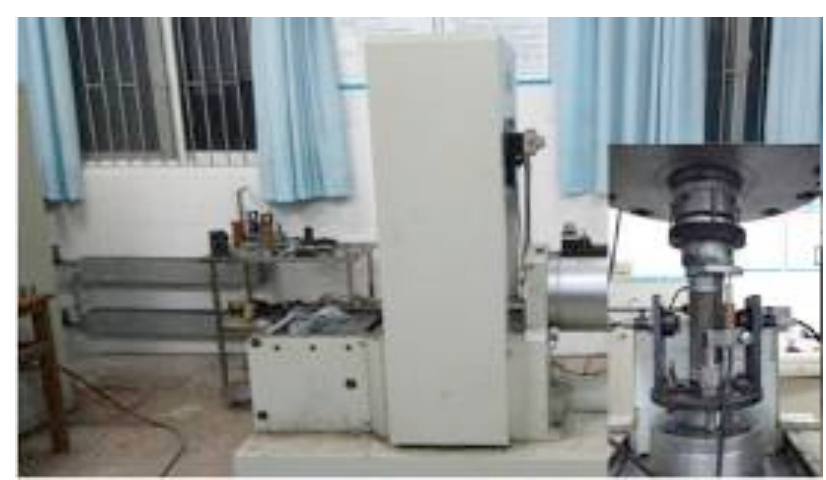

Fig. 2. Test equipment of RMT and the test loading process
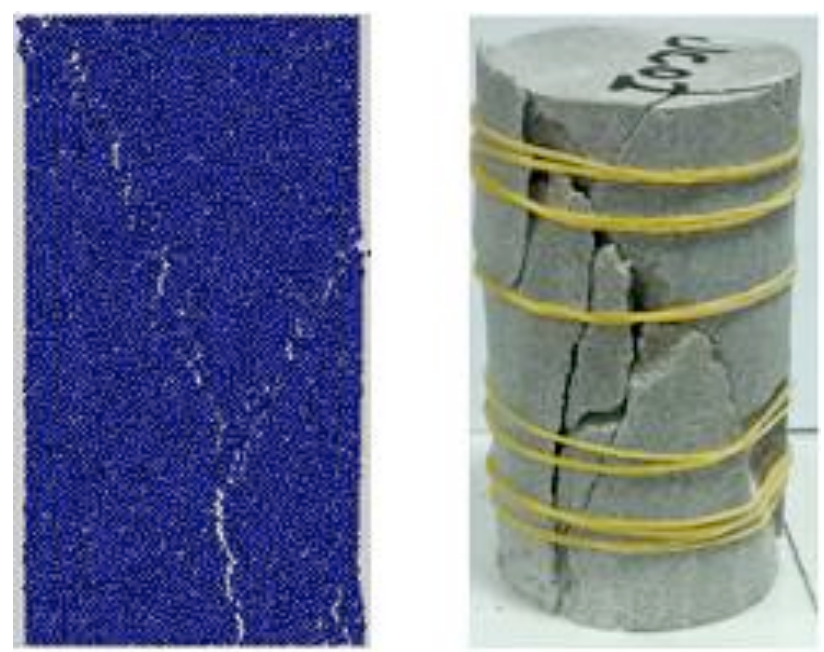

Fig. 3. Failure mode of rock specimen

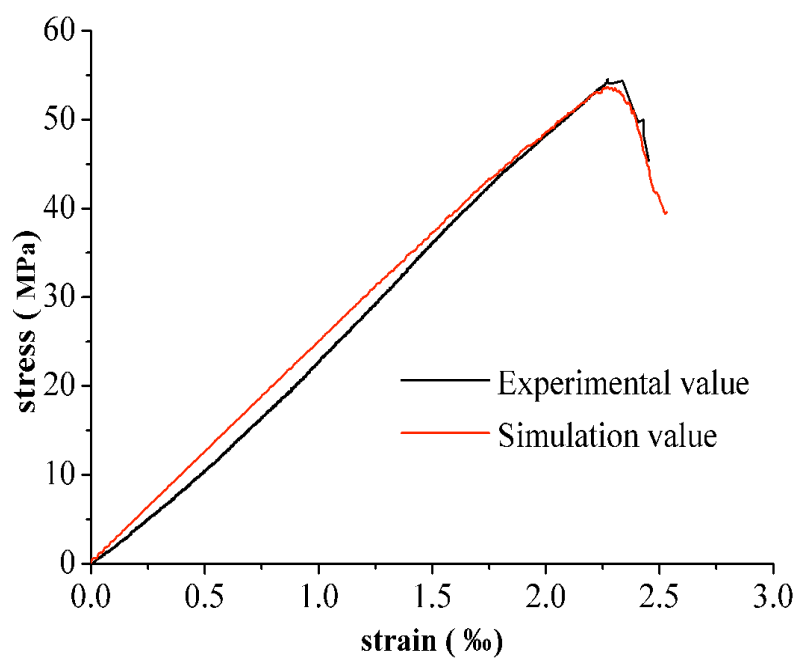

Fig. 4. Stress-strain curves of rock

The numerical simulation curve is consistent with the laboratory test curve, as shown in Fig. 4, illustrating the accuracy of the microscopic parameters that describe the macroscopic mechanical properties of rock specimens. In addition, the final failure characteristics are in accordance with the experimental results. The failure of the rock specimens, mainly tensile failure, is along the entire rock vertical plane and passing through the body. 
W. R. Liu, H. F. Ma, C. M. Li, J. Z. Li, Z. Q. Yin, Y. Li and C. Wang/

Journal of Engineering Science and Technology Review 9 (5) (2016) 164-170

Table 1. Microscopic parameters of particles

\begin{tabular}{c|c|c|c}
\hline Parameter & Magnitude & Parameter & Magnitude \\
\hline $\begin{array}{c}\text { Minimum } \\
\text { particle size } / \mathrm{mm}\end{array}$ & 0.35 & $\begin{array}{c}\text { Parallel bond } \\
\text { deformation } \\
\text { modulus/GPa }\end{array}$ & 15 \\
$\begin{array}{c}\text { Particle diameter } \\
\text { ratio }\end{array}$ & 1.66 & $\begin{array}{c}\text { Friction coefficient } \\
\text { Parallel bond normal }\end{array}$ & 0.5 \\
$\begin{array}{c}\text { Density } /\left(\mathrm{kg} / \mathrm{m}^{3}\right) \\
\text { stress/MPa }\end{array}$ & 2,000 & $\begin{array}{c}\text { Parallel bond shear } \\
\text { stress } / \mathrm{MPa}\end{array}$ & 50 \\
$\begin{array}{c}\text { Particle contact } \\
\text { modulus } / \mathrm{GPa}\end{array}$ & 15 & \multicolumn{3}{c}{} \\
\hline
\end{tabular}

\subsubsection{Uniaxial compression model of jointed rock}

The joint element can be characterized by the particle flow theory through the weakening particle bonding strength [8]. The uniaxial compression model of particle flow was established based on the above parameters. To analyze the influences of the single joint and cross double joints on rock strength characteristics, the joint dip angle of the single jointed rock was in the order $0^{\circ}, 15^{\circ}, 30^{\circ}, 45^{\circ}, 60^{\circ}, 75^{\circ}$, and $90^{\circ}$, respectively (Fig. 5); the cross double joint model had two joint planes that were represented by letters $a$ and $b$ (Fig 6 ), and the joint dip angle of $a$ and $b$ were also $0^{\circ}, 15^{\circ}, 30^{\circ}$, $45^{\circ}, 60^{\circ}, 75^{\circ}$, and $90^{\circ}$, respectively. Fig. 6 is a schematic diagram showing the dip angle of $a$ constant $\left(0^{\circ}\right)$, but changing the dip angle of $b$. Every joint dip angle of $a$ corresponds to seven different joint dip angles of $b$; thus, a total of $7 \times 7=49$ tests was performed. In the process of loading, the parallel bond strength of the joint was set at $5 \mathrm{MPa}$, and the loading rate was $0.01 \mathrm{~mm} / \mathrm{s}$.
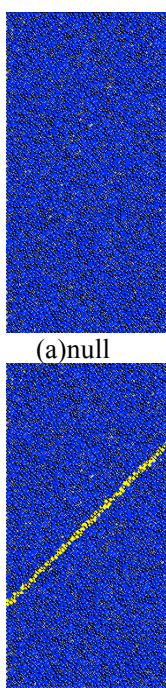

(e) $45^{\circ}$

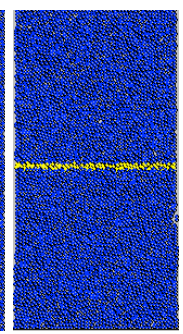

(b) $0^{\circ}$

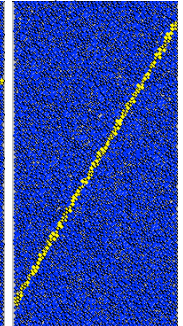

(f) $60^{\circ}$

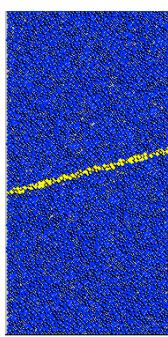

(c) $15^{\circ}$

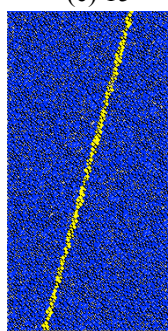

(g) $75^{\circ}$

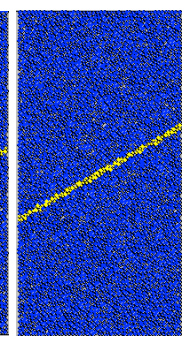

(d) $30^{\circ}$

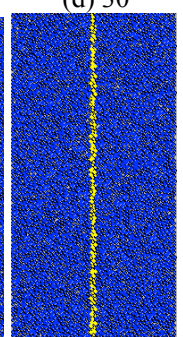

(h) $90^{\circ}$
Fig. 5. Different joint dip angles of single jointed rock model

\section{Result analysis and discussion}

\subsection{Mechanical properties of single joint in rock}

Fig. 7 shows the stress-strain curves of the rock specimen with different joint dip angles. The peak strength of the rock specimens with different joint dip angles is shown in Fig. 8. From Figs. 7 and 8 , in the uniaxial compression test, the peak strength of the specimens decreased first and then increased with the increase in the joint dip angle. The stressstrain curve of the non-joint specimen coincides with the curves of the joint dip angle $0^{\circ}, 15^{\circ}, 30^{\circ}$, and $90^{\circ}$; the rock mass strength is not affected by the joint. When the joint dip angle is $60^{\circ}$, the peak strength of the specimens is the smallest, which is 0.58 times of the non-joint specimen. The peak strength is sorted by descending order, and the sequence of the joint dip angle is $60^{\circ}, 75^{\circ}, 45^{\circ}, 30^{\circ}, 15^{\circ}, 90^{\circ}$, and $0^{\circ}$. The peak strength of the rock specimens with the increase of the joint dip angle is typical of the "U" type. Results are consistent with the results of the physical testing [16], which also proves the accuracy of the numerical simulation model.

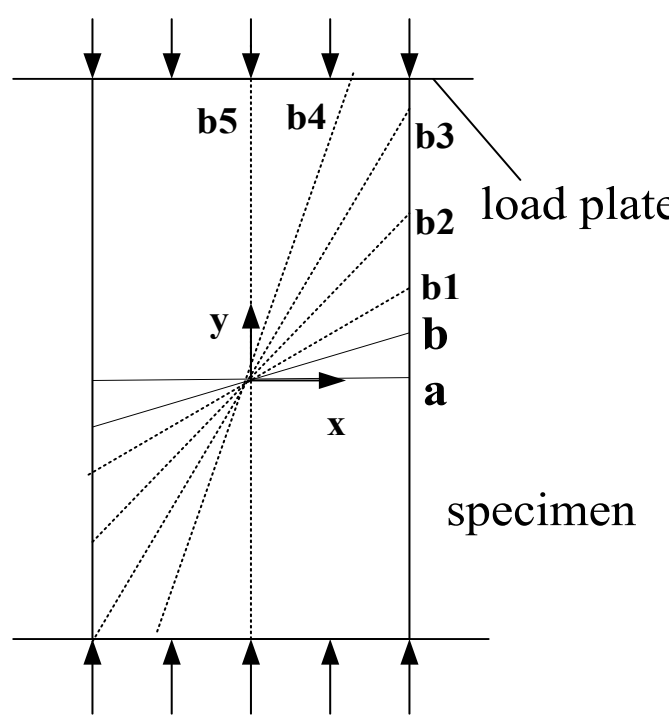

Fig. 6. Simulation scheme of cross double joints with different joint dip angles of $b$ (the joint dip angle of $a$ is $0^{\circ}$ )

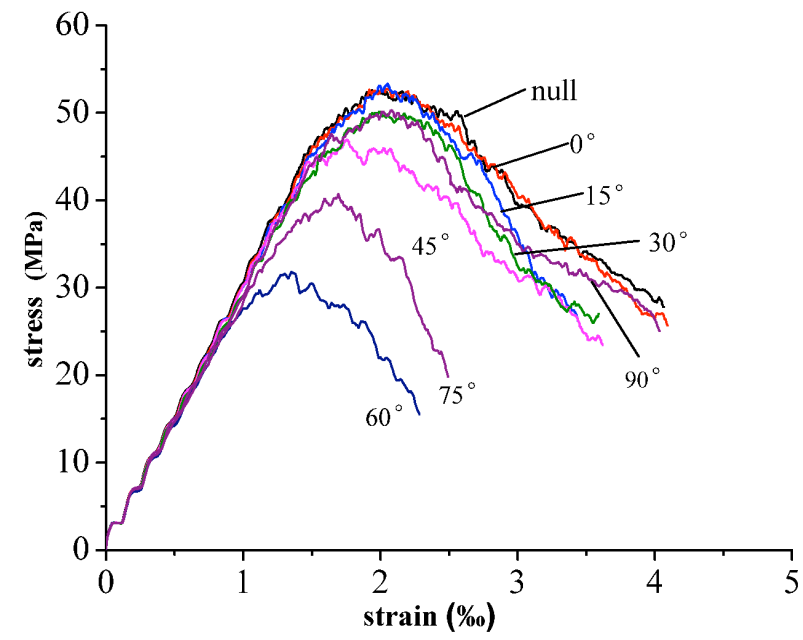

Fig.7. Stress-strain curves of rock specimens with different joint dip angles

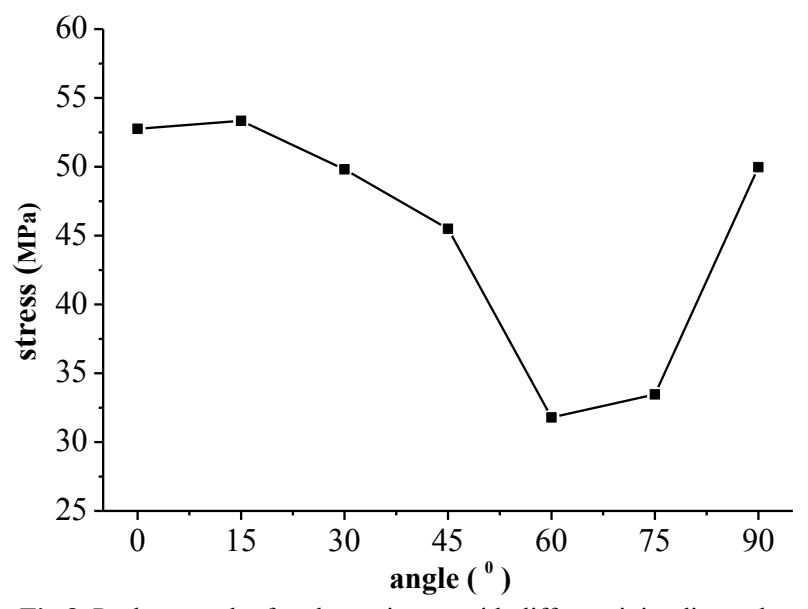

Fig.8. Peak strength of rock specimens with different joint dip angles 
The failure phenomena of the specimens appeared under an axial compressive force, and the failure modes differ with the different joint dip angles. The failure mode and distribution of microcracks were comprehensively analyzed. The results are shown in Fig. 9.

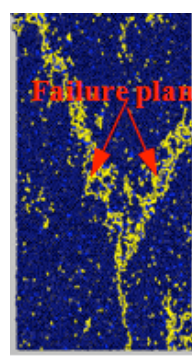

(a) null

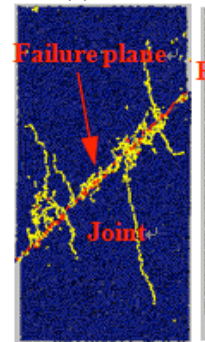

(e) $45^{\circ}$

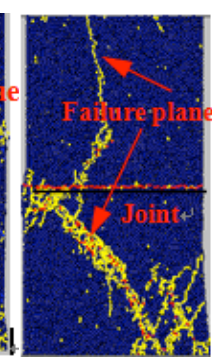

(b) $0^{\circ}$

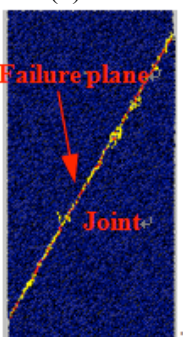

(f) $60^{\circ}$

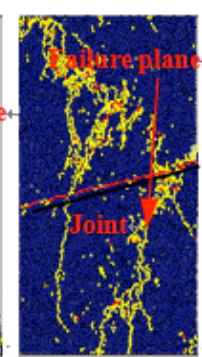

(c) $15^{\circ}$

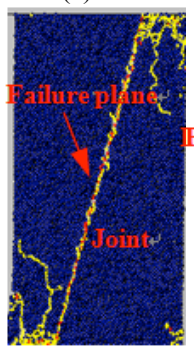

(g) $75^{\circ}$

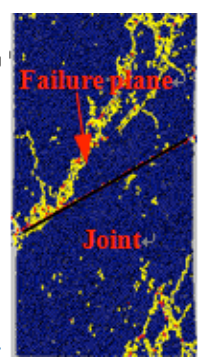

(d) $30^{\circ}$

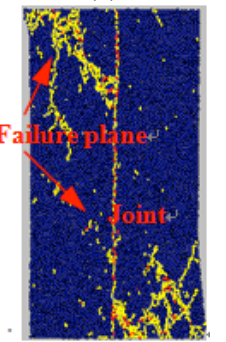

(h) $90^{\circ}$
Fig.9. The cracks distribution and failure mode of rock specimens with different joint dip angles

The failure mechanism of rock specimens was revealed from the point of microscopic cracks distribution. In Fig. 9, the cracks, formed by tension stress, are marked by the color yellow; the cracks formed by shear stress are represented in red. The position where cracks are distributed in large quantity is the macroscopic failure section. The peak strength of the rock specimens with the increase in the joint dip angle is typical of the "U" type. When the joint dip angle is between $0^{\circ}$ and $30^{\circ}$, cracks, mainly tensile cracks, develop and form fracture surfaces along the non-joint plane. The failure strength of the specimens is mainly loaded by the intact rock; thus, the strength is high, and the tensile failure is formed in the end. When the joint dip angles are between $45^{\circ}$ and $75^{\circ}$, several shear cracks, concentrated near the joint plane, appear at the joint position. The shear slip damage is formed mainly along the joint plane, and the failure strength of the specimens is loaded by the joint plane. The joint plane is a weak plane. The strength of rock specimens is low because of the low strength of the joint plane. When the joint dip angles are between $75^{\circ}$ and $90^{\circ}$, tensional slip damage develops along the joint plane. The failure strength of the specimens is loaded together by the intact rock and the joint plane; thus, the value is higher.

\subsection{Mechanical properties of cross double joints}

Based on the uniaxial compressive test for the rock specimens of cross double joints, the relationship between the joint dip angle and peak strength was analyzed. The specific values are described in Table 2.

When the joint dip angle of $a$ is $0^{\circ}, 15^{\circ}, 30^{\circ}$ and $90^{\circ}$, the peak strength is similar to that of the single joint, as shown in Table 2. The value is first decreased and then increased with the increase of the joint dip angle of $b$; the influence of the joint dip angle of $a$ on the rock mass strength is not obvious. The maximum peak strength value is about $51 \mathrm{MPa}$. The minimum peak strength occurs when the joint dip angle of $b$ is $60^{\circ}$; the value is about $31 \mathrm{MPa}$. When the joint dip angle of $a$ is $45^{\circ}, 60^{\circ}$ and $75^{\circ}$, the evolution law of the peak strength is also decreased first and then increased with the increase of the joint dip angle of $b$. However, the values of the peak strength significantly decrease (the maximum peak strength value is about $40 \mathrm{MPa}$; the minimum value is about $25 \mathrm{MPa}$ ), showing that the rock mass strength is affected by the joint dip angle of $a$. This phenomenon is a result of the superposition of the effects of the cross double joints on the rock mass strength. In addition, Table 2 also shows that when the dip angle of either joint is between $45^{\circ}$ and $75^{\circ}$, the rock mass strength is determined by the strength of this one joint. When the dip angles of both joints are between $45^{\circ}$ and $75^{\circ}$, the rock mass strength is determined by the combined effects of the strength of the two joints. When neither of the dip angles is between $45^{\circ}$ and $75^{\circ}$, the influence of the joints on the rock mass strength is little.

Table 2 Peak strength of rock specimens with different joint dip angles $(\mathrm{MPa})$

\begin{tabular}{c|c|c|c|c|c|c|c}
\hline $\boldsymbol{a}$ & $\mathbf{0}^{\circ}$ & $\mathbf{1 5}^{\circ}$ & $\mathbf{3 0}^{\circ}$ & $\mathbf{4 5}^{\circ}$ & $\mathbf{6 0}^{\circ}$ & $\mathbf{7 5}^{\circ}$ & $\mathbf{9 0}^{\circ}$ \\
\hline $\mathbf{0}^{\circ}$ & 52.1 & 52.2 & 48.3 & 45.6 & 31.2 & 35.4 & 49.2 \\
$\mathbf{1 5}^{\circ}$ & 51.4 & 52.7 & 47.1 & 42.8 & 32.8 & 34.7 & 50.9 \\
$\mathbf{3 0}^{\circ}$ & 49.6 & 51.3 & 46.6 & 40.3 & 30.1 & 33.6 & 45.6 \\
$\mathbf{4 5}^{\circ}$ & 40.9 & 41.6 & 40.2 & 35.6 & 28.8 & 30.5 & 40.7 \\
$\mathbf{6 0}^{\circ}$ & 34.8 & 33.2 & 30.3 & 26.1 & 25.1 & 29.6 & 33.8 \\
$\mathbf{7 5}^{\circ}$ & 38.9 & 40.6 & 39.2 & 33.6 & 26.8 & 31.7 & 39.7 \\
$\mathbf{9 0}^{\circ}$ & 50.5 & 52.1 & 49.1 & 44.3 & 32.2 & 35.9 & 48.6 \\
\hline
\end{tabular}

The stress-strain curves, peak strength, and the failure modes were analyzed in detail below when the joint dip angle of $a$ is $0^{\circ}$ or $60^{\circ}$ to study the influences of cross double joints on the mechanical properties more clearly. The results of the other conditions are similar and are not to be described in this report.

\subsubsection{The joint dip angle of $a$ is $0^{\circ}$}

The complete strain-stress curves of the rock specimens are shown in Fig. 10.

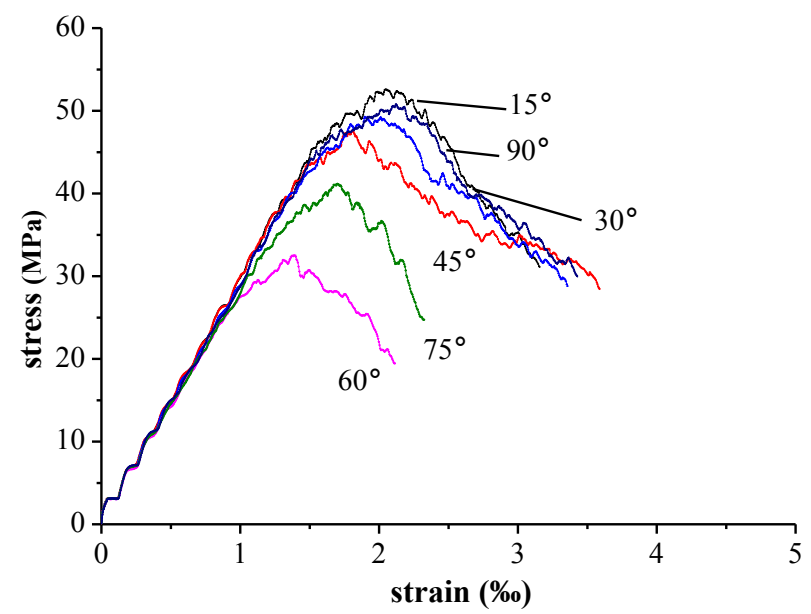

Fig. 10 Stress-strain curves of rock specimens

The trend of the curves in Fig. 10 is consistent with that of the single joint, that is, the peak strength of the rock specimens is decreased first and then increased with the increase in the joint dip angle of $b$. The curves of the joint dip angle $0^{\circ}, 15^{\circ}, 30^{\circ}$, and $90^{\circ}$ are coincident. When the joint dip angle is $60^{\circ}$, the peak strength of the specimens is the minimum. The failure mode is also the same as that of the single joint. When the joint dip angle is less than $30^{\circ}$, the 
failure of the whole rock mass is the result of the partial failure of the upper and lower end faces. When the joint dip angle is $45^{\circ}, 60^{\circ}$, and $75^{\circ}$, the slip failure of the specimens occurs along the joint plane. When the joint dip angle is $90^{\circ}$, the failure is developed in the upper-right and lower-left corners of the specimens. Thus, the rock mass strength is affected by the joint dip angle of $b$, not $a$.

\subsubsection{The joint dip angle of $a$ is $60^{\circ}$}

Fig. 11 shows the peak strength of rock specimens with different joint dip angles of $b$.

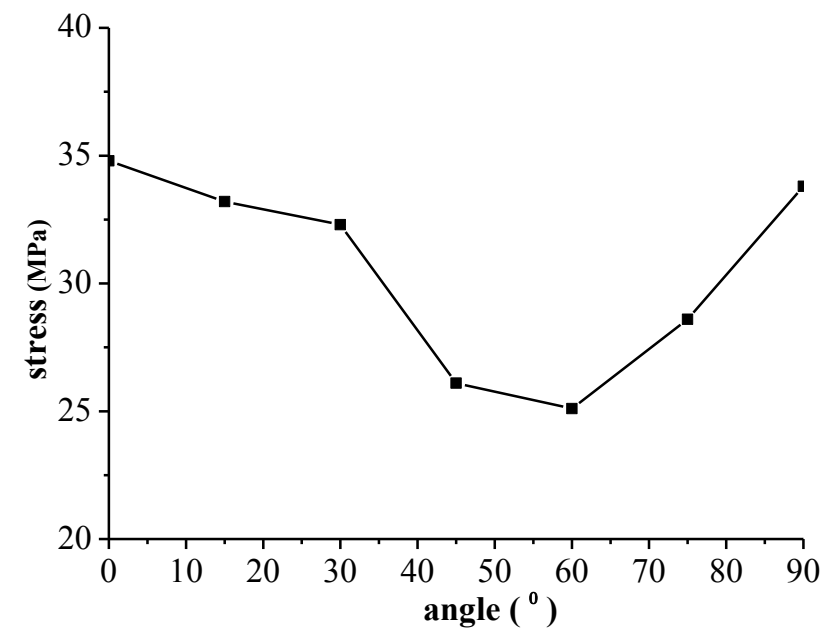

Fig.11. Peak strength of rock specimens with different joint dip angles

The peak strength of rock specimens markedly decreased; the maximum value is $34.8 \mathrm{MPa}$ with a $34.8 \%$ decrease, compared with $52.1 \mathrm{MPa}$ (the maximum value of the peak strength when the joint dip angle of $a$ is $0^{\circ}$ ). The trend of the peak strength of the rock mass is first decreased to a minimum value (the value is $25.1 \mathrm{MPa}$ when the joint dip angle of $b$ is $60^{\circ}$ ) and then increased with the increase in the joint dip angle. This condition proves that the mechanical property of the rock mass is significantly affected by the superposition of the double joints; resultantly, the rock mass strength is lower than that of the single joint.

Fig. 12 shows the displacement vector distribution of the rock specimens under the failure condition.

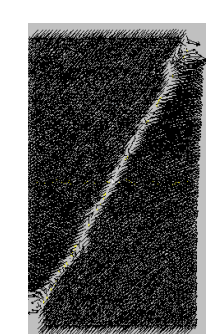

(a) $0^{\circ}$

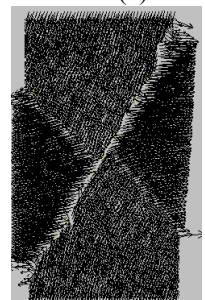

(d) $45^{\circ}$

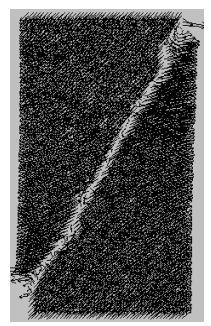

(b) $15^{\circ}$

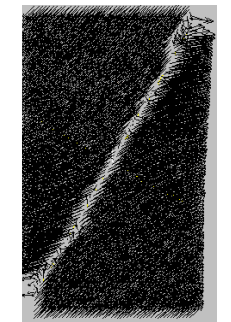

(c) $30^{\circ}$

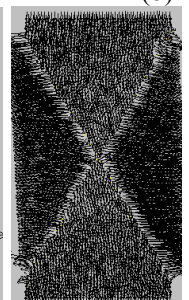

(e) $60^{\circ}$

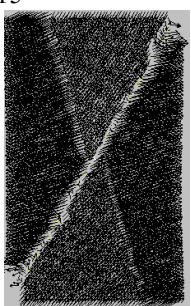

(f) $75^{\circ}$

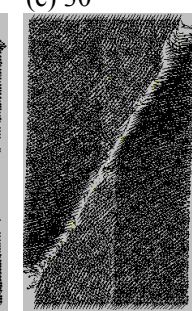

(g) $90^{\circ}$
Fig.12. Displacement vector distribution of rock specimens
The influences of joint $a$ on the failure mode of the rock specimens are significant; with the differences of the joint dip angle of $b$, great differences exist in the failure mode. When the joint dip angle of $b$ is less than $30^{\circ}$, the failure, mainly slip failure, is developed along joint $a$ without the influences of joint $b$. When the joint dip angle of $b$ is $45^{\circ}$, $60^{\circ}$, and $75^{\circ}$, the slip failure of the rock specimens is formed as the "X" type along joints $a$ and $b$. The cross failure planes that are formed at the joint dip angle of $60^{\circ}$ are more obvious than that formed at the joint dip angle of $45^{\circ}$ and $75^{\circ}$. When the joint dip angle is $90^{\circ}$, the failure is also developed along joint $a$; the influence of joint $b$ is not obvious. Based on the analysis above, when the joint dip angle of $a$ is $60^{\circ}$ and the joint dip angle of $b$ is between $45^{\circ}$ and $75^{\circ}$, the cross double joints have a significant effect on the mechanical properties of a rock mass; that is, the failure strength greatly decreases, and the failure modes are different.

\section{Conclusions}

The mechanical properties of the joint rock with different dip angles and cross double joints were analyzed in detail by the combination of the theoretical calculation and the numerical simulation methods to explore the effects of joints on rock mechanical properties. The conclusions obtained are as follows:

(1) The joint rock mass strength with the different dip angles has obvious angle-range effects. The failure strength of the specimens is loaded by the joint plane when joint $\beta$ is between $45^{\circ}$ and $75^{\circ}$. Therefore, the slip failure mainly forms along the joint plane. However, if $\beta$ is not between those ranges, the effects of the joint on the failure are little, and the rock mass failure will be developed along the other section that intersects with the joint plane.

(2) For the rock mass of cross double joints, the rock mass strength is significantly affected by the dip angles of the double joints. The rock mass strength is determined by the strength of the joint where the dip angle is between $45^{\circ}$ and $75^{\circ}$. If both joints are between $45^{\circ}$ and $75^{\circ}$, the failure is formed because the " $\mathrm{X}$ " type is the result of the combined effects of the strength of the two joints. If neither of the two joints is between $45^{\circ}$ and $75^{\circ}$, the influences of the joint planes on rock mass strength are little.

This study analyzed the joint rock mass strength of the different dip angles by both the theoretical calculation and numerical simulation methods and obtained the laws of rock failure based on the cross double joints model, which was established by the numerical simulation method. Thus, this study has an important guiding significance for the engineering practice to understand the complex structure of rock mass. However, no in situ monitoring data are available. Therefore, in future studies, actual field conditions will be further considered, and the measured results will be analyzed in combination with the model analysis in this study.

\section{Acknowledgements}

The study was supported by the National Natural Science Foundation of China (NO. 51304007, NO.51504005), the State Key Program of National Natural Science Foundation of China (U1361208), Anhui Provincial Natural Science Foundation (1408085MKL42, 1408085MKL41). 


\section{References}

1. Wong L. N. Y., Einstein H. H., "Crack coalescence in molded gypsum and Carrara marble: Part 2-Microscopic observations and interpretation", Rock Mechanics and Rock Engineering, 42(3), 2009, pp. 513-545.

2. Yang S. Q., "Study of strength failure and crack coalescence behavior of sandstone containing three preexisting fissures", China Journal of Rock and Soil Mechanics, 34(1), 2013, pp.31-39.

3. Cundall P. A., Strack O. D. L., "A discrete numerical model for granular assemblies", Geotechnique, 29(1), 1979,pp. 47-65.

4. Asadi M., Rasouli V., Barla G., "A bonded particle model simulation of shear strength and asperity degradation for rough rock fractures", Rock Mechanics and Rock Engineering , 45(5), 2012, pp. 649-675.

5. Yoon J., "Application of experimental design and optimization to PFC model calibration in uniaxial compression simulation", International Journal of Rock Mechanics and Mining Sciences, 44(6), 2007, pp.871-889.

6. Potyondy D. O., Cundall P. A., "A bonded-particle model for rock", International Journal of Rock Mechanics and Mining Sciences, 41(8), 2004,pp.1329-1364.

7. Eberhardt E., Stead D., Coggan J. S., "Numerical analysis of initiation and progressive failure in natural rock slopes-the 1991 Randa rockslide", International Journal of Rock Mechanics and Mining Sciences , 41(1),2004,pp.69-87.

8. Wang C., Tannanta D. D., Lillyb P. A., "Numerical analysis of the stability of heavily jointed rock slopes using PFC2D", International Journal of Rock Mechanics and Mining Sciences, 40(3),2003, pp. 415424.
9. Vergara M. R., Van Sint J. M., Lorig L., "Numerical Model for the Study of the Strength and Failure Modes of Rock Containing NonPersistent Joints", Rock Mechanics and Rock Engineering, 49(4),2016.pp.1211-1226.

10. Prudencio M., Van Sint J. M., "Strength and failure modes of rock mass models with non-persistent joints". International Journal of Rock Mechanics and Mining Sciences, 44(6), 2007, pp.890-902.

11. Ghazvinian A., Sarfarazi V., Schubert W., Blumel M., "A study of the failure mechanism of planar non-persistent open joints using PFC2D", Rock Mechanics and Rock Engineering, 45(5), 2012, pp.677693.

12. Wu S. C., Zhou Y., Gao L. L., et al, "Application of equivalent rock mass technique to rock mass engineering", Chinese Journal of Rock Mechanics and Engineering, 29(7), 2010, pp.1435-1441.

13. Park J. W.; Song J. J., “ Numerical simulation of a direct shear test on a rock joint using a bonded-particle model", International Journal of Rock Mechanics \& Mining Sciences, 46 (8), 2009, pp.1315-1328.

14. Bahaaddini M., Sharrock G., Hebblewhite B. K., "Numerical direct shear tests to model the shear behaviour of rock joints", Computers and Geotechnics, 51(6), 2013, pp.101-115.

15. Li T. L., Tan X. S., Liu W. W., "Rock mass mechanics", Chongqing : Chongqing University Press, China ,1990, pp 50-130.

16. Zhang G. M., Li Y. P., Yang C. L., et al, "Physical simulation of the deformation and failure mechanism of soft and hard interbedded salt rocks", Chinese Journal of Rock Mechanics and Engineering, 31(9), 2012, pp.1813-1820. 